\title{
Wartime Crisis Perceptions Effects on Political Advertising Effectiveness: The Moderating Role of Political Involvement
}

\author{
Ali Bassam Mahmoud* \\ Ton Duc Thang University, Ho Chi Minh City, Vietnam \\ ali.bassam.mahmoud@tdtu.edu.vn \\ Nicholas Grigoriou \\ Monash University, Clayton, VIC, Australia \\ nginasia@ hotmail.com \\ William D Reisel \\ St John's University, Staten Island, NY, USA \\ reiselw@stjohns.edu \\ Dieu Hack-Polay \\ University of Lincoln, Lincoln, United Kingdom \\ DHackpolay@lincoln.ac.uk
}

\begin{abstract}
This study addresses the effectiveness of political advertising in an extreme context, i.e., in wartime. A self-administered cross-sectional survey was used to collect data during 2016 parliamentary elections in Syria. Structural equation modelling was conducted to test the hypothetical model and its invariance related to political involvement. Our results showed that beliefs are a 4-dimension structure consisting of information, veracity, sarcasm, and cynicism. Further, wartime perceptions were found to negatively affect attitude via sarcasm among politically less involved voters. Negative attitude was found to be linked to lower levels of veracity among less involved voters and to higher levels of cynicism for those who are highly involved in politics. Negative attitudes regarding political advertising was found to lower the chances for watching advertisements, supporting a candidate, and voter to have a willingness to vote. We also found that paying attention to political advertising doesn't relate to voter's intention to vote.
\end{abstract}

Keywords: War; Dictatorships; Political Marketing Communication; Beliefs; Attitudes; Middle East 


\section{INTRODUCTION}

Our review of prior research revealed there is relatively little that is known about voters' attitudes and behaviour related to political advertising in dictatorships or war-torn nations (i.e., Syria). This may be a function of the challenges and risks of performing scientific research in the world's least peaceful region (Global Peace Index, 2018). There is general agreement that Syria is one of the most dangerous countries in the world according to Global Peace Index (2018).

Most research in political advertising to date has addressed political campaigning on voters' attitudes and beliefs from a Western perspective. A neglected area of academic research interest is the attitudes and beliefs towards political advertising from a Middle Eastern perspective. The Middle East region consists of Arab as well as non-Arab democracies such as Israel and Turkey, neighbouring dictatorships found in Iran and Syria, and Kingdoms in Saudi Arabia and Jordan. Within the region, communal alliances play a vital role in understanding political process. In particular, tribes and clans are influential throughout the Middle East and their members share common attitudes towards political phenomena (Goodarzi, 2009). Western scholars have frequently asked if popular attitudes and beliefs present an obstacle to democratization in the region. These popular beliefs and attitudes result from the religious traditions that predominate in most Arab countries and may inhibit the emergence of a democratic political culture (Tessler, 2002).

Research into cultural differences suggests that the West is universal, rational, pluralist and secular, whereas the East is particularistic, traditional, despotic, and religious obscurantism (Bromley, 1994). As such, the turbulent and often uncertain nature of Middle East politics provides fertile ground for examining political advertising effectiveness. Accordingly, our study attempts to address this knowledge gap by empirically validating a conceptual model predicting voters' turnout behaviour based on voters' wartime perceptions, beliefs and attitudes regarding political advertising in dictatorships. Further, we investigate whether our proposed model effects may be moderated by voters' political involvement. Syria as a modern example of a war-torn dictatorship that is the object of much polemics yet has a limited body of scholarly inquiry (Mahmoud and Reisel, 2015). We propose and test a research model empirically using time-sensitive Syria data from the 2016 parliamentary elections.

\section{LITERATURE REVIEW AND CONCEPTUAL MODEL}

\section{Attitudinal and Behavioural Outcomes towards Political Advertising}

The Syrian war began in March 2011 over what was then a government crackdown on political dissent leading to arrests and torture of teenagers accused of painting revolutionary graffiti in the city of Daraa (CNN, 2017). Syrian forces fired on protestors leading to several deaths and prompting unrest to spread throughout Syria. Since then, more than 400,000 Syrians have been killed and over half the 22 million population of Syria has been displaced from their homes either throughout Syria or to neighbouring countries (United Nations, 2016). By studying political 
advertising in a war-torn Syria, we collected primary data to better understand how this context influences beliefs and attitudes about political advertising.

Politicians and political parties spend considerable sums of money on advertising that focuses on influencing voters (Jin et al. 2009). This was certainly the case in the 2016 Syrian elections. Yet the impact is not predictable as some voters are highly critical of advertising whereas others respond very favourably (Kaid 2004). What then, makes political advertising effective? The answer to this question seems to reside with an understanding of the prior attitudes and beliefs of voters (Gamson 1992). There are several antecedents to the understanding of voters' attitudes and beliefs including the credibility of the advertising source (Anderson 1981), the choice of media (Stroud 2008), and the degree to which voters have already established an initial belief regarding politicians or their party (Taber and Lodge 2006).

An understanding of voters' beliefs and attitudes regarding political advertising is frequently attributed to a range of different of voters' perceptions (Jin et al. 2009). As such, scholars have addressed political advertising from multiple perspectives. For instance, political advertising has been examined from the view point of choice of candidate (Johnston et al. 2004), voter turnout (Vavreck, 2007), voter emotion (Brader, 2005), political advertising's ability to motivate voters (Brader 2005), political advertising targeting youth (Waller and Polonsky, 1999) and cultural differences in political advertising (Kaid and Holtz-Bacha 1995).

Jin et al. (2009) empirical study was the first endeavour to identify a voter's belief structure regarding political advertising. They revealed five dimensions of beliefs that are the raison d'être of voters favourable or unfavourable attitudes toward political advertising. Below is a description of each dimension.

- Information: the political advertising provides information about candidates to help the voters make informed decisions and gain political knowledge.

- Veracity: political advertising can be criticized for delivering false, dishonest, exaggerated, deceptive or misleading information or claims which may affect the voter's decision. Moreover, political advertising can ruin the reputation of the advertising industry and the credibility of advertising as a reliable source of information in general (Iyengar and Prior, 2002). There have been many voices calling state authorities to regulate political advertising and to hold politicians accountable for their claims during the elections (Gleason, 1996). However, in practice, monitoring political advertising is very challenging if not impossible (Parker, 2016).

- Cynicism: A harsh feeling about political advertising can be stimulated by advertising's content negativity. Nonetheless, negative political advertising has been praised by some advocates for its effectiveness, that is, many politicians in many elections around the globe have adopted attacking advertisements against their opponents to take them down (Westen, 2012).

- Money politics: Large amounts of money are usually invested into political advertising campaigns. It is unclear if this use of money feeds corruption or spreading dominating ideologies. Jin et al. (2009, p. 563) describes political advertising as "the power of money in politics."

- Entertainment: Consumers tend to like pleasing advertisements. Studies conducted in the Middle East have reported significant relationships between the advertising's entertainment value and overall voters' attitudes toward advertising (Mahmoud, 2013, 2015; Mahmoud et al. 
2019). Many politicians tend, through their advertisements, to exhibit sarcastic attitudes and make fun of their rivals. In Syria, political advertisements were satirized by media during the 2016's parliamentary election, and many Syrian people described the way the campaigns were run as a farce. In this study we use the term of sarcasm (instead of entertainment) as an alternative to the hedonic component of beliefs about political advertising.

Recent studies on attitudes toward advertising have concluded robust links between attitudes and behavioural responses toward advertising (Mahmoud, 2015). These links have their roots in national culture and determine how consumers within national cultures make consumption decisions (Rawwas et al. 1998). Indeed, as Rawwas et al. (1998) further assert, often such consumption decisions are made in cultures directly affected by war. Research in behavioural responses to advertising is a function of consumers' beliefs, that is, that an event or state of affairs has or will occur (Eagly and Chaiken, 1998), or their attitudes, namely, the positive or negative cognitive dispositions that one person holds towards a referent (Mahmoud, 2013). In the present study, we explore three intentional or behavioural responses regarding 2016 Syria's parliamentary advertising campaigns. Specifically, we examine the extent to which the participants are watching or paying attention to political advertising, if they are supporting a candidate(s), and if they are intending to vote (that is, turnout intention).

\section{Conceptual Model}

Online newspapers ran anecdotal polls during the elections in Syria to explore voter opinions about political advertising campaigns. Most of those surveys show that voters hold unfavourable attitudes toward political advertising. In light of this, we posit

H1: Syrian voters hold negative beliefs, attitudes and behavioural responses regarding political advertising.

The civil war in Syria has cost the lives of hundreds of thousands of people and has displaced nearly half of the population since 2011. The war has affected Syrians in nearly all aspects of everyday life. For the majority, purchasing power and incomes have decreased. Yet, some have profited by acting as so called "war traders" who have been exploiting their links with the government or the opposition factions to control the basic commodities traded in the country. War traders have made fortunes at the expense of the many seeking to ensure very basic needs (food, water, fuel). In this respect, perceptual variables may be affected by wartime as evidenced by very few studies (Mahmoud and Resiel, 2015) who found that war increases perceptions of job insecurity. Thus, the effectiveness of marketing communications (for example, political advertising) can be affected during a wartime. Further, our study examined political candidates and their advertisements from different competing political parties. This leads us to posit hypothesis 2:

$\mathrm{H} 2$ : Wartime perceptions are positively related to beliefs about political advertising.

Numerous studies have validated the path beliefs $\rightarrow$ attitude $\rightarrow$ behavioural intentions in diverse contexts including those in the Middle East (e.g., Mahmoud et al. 2019). For instance, effective advertising could enhance the chances for purchase intentions toward advertised products (Sathish 
et al., 2011). In political advertising, products are the candidates themselves who aim, through their advertising, to persuade and encourage voters to engage in political life, which implies, watching the advertising, supporting a candidate, and voting in favour of those candidates. We therefore posit:

H3: Beliefs are positively related to attitudes, regarding political advertising.

H4: Attitudes are positively related to behavioural responses toward political advertising.

\section{METHODS}

The study was conducted in a wartime context in Syria during the parliamentary elections of 2016. Our sample includes Syrian citizens of voting age. Based on the Syrian state's announcements on the number of qualified voters, our research population was nearly eight million people, including the military and police forces, given the amendments to the Syrian electoral law in 2014 (Public Election Law, 2016). We constructed a self-administered cross-sectional survey that was distributed upon the commencement of the electoral marketing campaigns. Participants were reluctant to take part in a survey containing sensitive questions about politics due to potential fears of recrimination that would be held by anyone living in a war-torn nation (for example, the respondents might not be assured that the researchers were not in fact governmental intelligence agents, even if confidentiality were stated). To address this concern, data were collected in the privacy of the respondents' homes. Further, we used a snowballing sampling approach given the extreme context of this study. Despite the known limitations of snowball sampling (Waters, 2015), snowball sampling enabled us to rely on the participants to find additional respondents (Horst, 2016). The survey instrument was designed to measure the public's wartime perceptions, beliefs and attitudes about political advertising, political involvement, watching political advertisements, supporting candidates, intention to vote, and demographics. We collected, 215 usable responses.

We measured Wartime perceptions using single item designed for the current study with reference to Mahmoud and Reisel's (2015) work. The item was 'I'm negatively affected by the country's war" to capture the overall perceived negative impact of the civil war on respondents' lives. The set of beliefs about political advertising was measured using an adapted version of the multidimensional scale developed by Jin et al (2009). Sample items for each dimension were "political advertising is a valuable source of information about candidates" for information, "it feels like I've got to laugh whenever I look at political advertising" for entertainment / sarcasm, "Political advertising is a good use of campaign funds" for money politics, "In general, political advertising is truthful" for veracity, and "political advertising makes members of the public more interested in politics" for cynicism, Attitude toward political advertising was measured using Jin et al, (2009) uni-dimensional scale. A sample item is, "in general, I like political advertising." Political involvement, watching political advertising, supporting a candidate, and intention to vote were all measured on a single-item basis. Representing items were, respectively, "I'm interested in politics," and "During 2016 elections, I watch or pay attention to candidates' advertising," and "Do you support or trust any of the candidates in the 2016 elections?" and "Will you vote in 2016 elections?" Quantitative analyses were used to analyse the data. Those included one-sample t-tests to evaluate the different levels of beliefs and attitudes, structural equation modelling to test the proposed structural model and its invariance related to political involvement. Moreover, we used 
another procedure of SEM to run a confirmatory factor analysis and assess the dimensionality of the beliefs' set. We also used bootstrapping in the analysis of mediated effects.

Based on Jin, et al (2009) results, we tested the assumption that beliefs about political advertising were a five-dimensional structure. Our statistics, RMESA $=.050<0.08$, SRMR $=.0515<.08$, $\chi^{2} / \mathrm{df}=1.532<3, \mathrm{NFI}=.904>.9$, and CFI $=.964>.9 \mathrm{had}$ an initial support for Jin et al, (2009) theory that beliefs about political advertising are a five-factor construct, however, money politics was unsuccessful in meeting the minimum of Cronbach's alpha (.7) recommended by Nunnally and Bernstein (1994) and Peterson (1994) for 3- (or above) item constructs. Money politics scored .668 on reliability test without any possible if-item-deleted improvements for the scale. Thus, money politics was removed from the structural model and we re-ran the confirmatory factor analysis again. Consequently, our statistics improved after dropping money politics (RMESA = $.044<0.08, \mathrm{SRMR}=.048<.08, \chi 2 / \mathrm{df}=1.418<3, \mathrm{NFI}=.93>.9$, and $\mathrm{CFI}=.98>.9$ ) and showed that beliefs about political advertising in Syria is rather a 4-factor structure, comprising information $(\alpha=.824)$, sarcasm $(\alpha=.731)$, veracity $(\alpha$ spearman-Brown $=.722)$, and cynicism $(\alpha=$ .735). Interestingly, this five-dimension structure was found to be invariant among our sample participants whether they were involved or not involved in politics ( $\triangle$ CFI never exceeded .001 ). Attitude as a multi-item unidimensional factor was also found to be internally consistent $(\alpha=.812)$, an example item was "In general, I like political advertising." Table 1 presents the main variables in the study in inter-correlation matrix along with the values of mean and standard deviation for each variable.

\section{RESULTS}

215 respondents participated in the study. Sixty-six percent were male, and 34 percent were female. The vast majority of the participants were highly educated holding a college bachelor's degree or higher $(96.7 \%)$. A majority of the participants worked in the private sector (58\%) with twelve percent working in the public sector. Twenty-five percent were retired or unemployed and 5 percent were self-employed. The majority (70 percent) of the respondents answered that they would not vote in the 2016 election or that they did not trust any candidates (76\%). Such decline in the confidence of governments is not uncommon (Nye, Zelikow, and King, 1997). Participants reported that they got their news from three major sources: internet and social media (94\%), television news (57\%) and newspapers (39\%).

$\mathrm{H} 1$ is tested using one-sample t-test to assess public's beliefs and attitudes regarding political advertising, against the neutral value (i.e., 3). We found that, as hypothesized, all beliefs and attitudes are negative toward political advertising. Therefore, H1 is fully supported

Although most of the goodness-of-fit measures indicate that the conceptual model fits our data, (GFI) is .893 lower than .9. Further, some paths are seen to be non-significant. Therefore, nonsignificant paths are eliminated, and another path analysis was conducted to produce an alternate model (see Figure 1) which represents our findings. The major fit indices, i.e., $\square^{2} / \mathrm{df}=1.664<3$, $\mathrm{CFI}=.942>.9, \mathrm{GFI}=.920 \in[.9, .95], \mathrm{SRMR}=.054<.08, \mathrm{RMSEA}=.056<.08$, suggest that the alternate path model attests to a well fit for the observed data. Moreover, all mediations are tested using bootstrapping approach and all found to be significant. 
Table 1: Descriptive statistics and inter-correlations

\begin{tabular}{|c|c|c|c|c|c|c|c|c|c|c|c|}
\hline Dimension & $\overline{\mathbf{X}}$ & SD & 1 & 2 & 3 & 4 & 5 & 6 & 7 & 8 & 9 \\
\hline Information & 1.75 & 0.83 & & & & & & & & & \\
\hline Sarcasm & 3.30 & 1.13 & $-.28 * *$ & & & & & & & & \\
\hline Veracity & 1.60 & 0.70 & $.54 * *$ & $-.20 * *$ & & & & & & & \\
\hline Cynicism & 3.96 & 0.92 & $-.56 * *$ & $.25^{* *}$ & $-.50 * *$ & & & & & & \\
\hline Attitude & 2.10 & 0.95 & $.61 * *$ & $-.45^{* *}$ & $.57 * *$ & $-.63 * *$ & & & & & \\
\hline Wartime Perceptions & 4.50 & 0.87 & -0.08 & 0.12 & -0.04 & 0.09 & -0.09 & & & & \\
\hline Watching PAds & 2.25 & 1.27 & $.19 * *$ & $-.16^{*}$ & $.19 * *$ & $-.31 * *$ & $.21 * *$ & -0.13 & & & \\
\hline Intent to Vote & 0.31 & 0.46 & $.26^{* *}$ & $-.33 * *$ & $.17 *$ & $-.32 * *$ & $.38 * *$ & -0.02 & $.16^{*}$ & & \\
\hline Supporting a Candidate & 0.24 & 0.43 & $.21 * *$ & $-.25 * *$ & $.19 * *$ & $-.25 * *$ & $.31 * *$ & -0.05 & $.23^{* *}$ & $.56^{* *}$ & \\
\hline Political Involvement & 0.50 & 0.50 & -0.13 & 0.13 & $-.15^{*}$ & $.20 * *$ & $-.16^{*}$ & 0.04 & 0.09 & -0.01 & 0.02 \\
\hline
\end{tabular}

We conducted an invariance test to analyse the moderating role of political involvement. We found that $\triangle$ CFI is (.01) higher than .001 (Byrne, 2010), which demonstrates a significant variance (regarded to political involvement levels) in the alternate model between two groups of people that are either involved or not involved in politics. Therefore, we conducted pairwise parameter comparisons using $\mathrm{Z}$ score to detect moderated paths. Our results demonstrate that political involvement moderates the path from wartime perceptions to sarcasm, from sarcasm to attitude, from veracity to attitude, and finally from cynicism to attitude. We conclude that wartime perceptions are positively related to sarcasm for only respondents who're politically indifferent $\left(\beta_{1}\right.$ $=.362)$ (refer to Figure 1). These effects are transmitted to attitude via sarcasm $(\mathrm{B}=-0.077, \mathrm{P}<$ $.01)$ whereas, wartime perceptions little effect on politically involved voters regarding their sarcasm perception toward political advertising $\left(\beta_{2}=.032\right)$. However, both politically involved and non-involved participants hold unfavourable attitude toward political advertising because they believe that political advertising is sarcastic. Sarcasm effects on attitudes are stronger for those who are non-politically involved $\left(\beta_{1}=-.388>\beta_{2}=-.207\right)$. Additionally, people with low levels of political involvement are seen to hate political advertising because the lack of veracity $\left(\beta_{1}=.858\right)$, whereas those with high degree of political interests dislike political advertising immersed in cynicism $\left(\beta_{2}=.833\right)$.

For all respondents, positive attitudes toward political advertising is linked to positive behavioural responses, therefore respondents are more like to pay attention to political advertising $(\beta=.288)$, favour a candidate $(\beta=.367)$, and/or be willing to vote $(\beta=.261)$. Our results show that having a candidate to support is positively related to intention to vote $(\beta=.462)$.

Based on our analysis results, we found that H1, H4, H5, H6, and H8 are fully supported, H2 and $\mathrm{H} 3$ are partially valid, whereas $\mathrm{H} 7$ is rejected, therefore holding favourable watching or paying attention to political advertising doesn't relate to voter's intention to vote. 
Figure 1: Alternate model

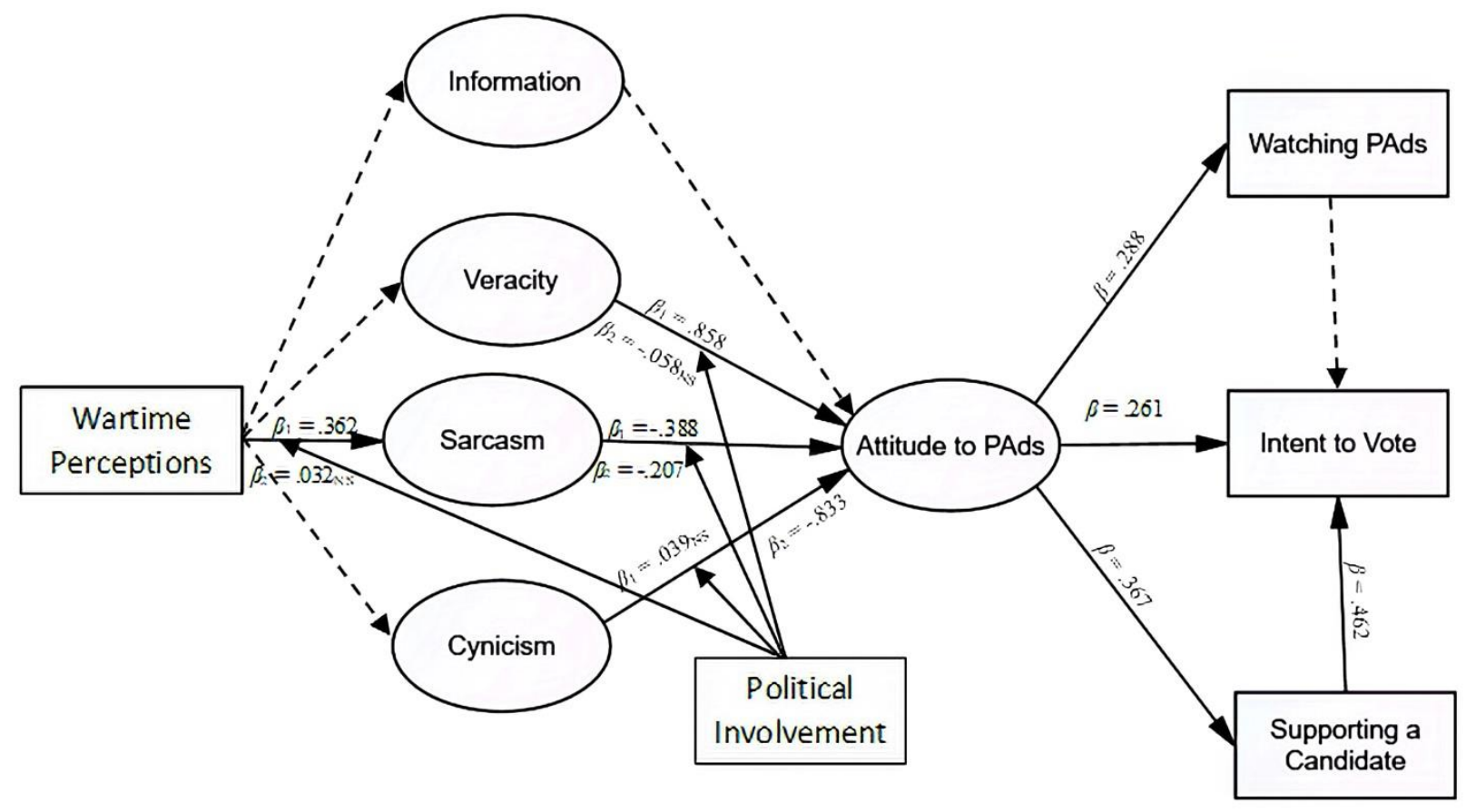

Note. Dashed arrows or coefficients subscripted with ' $N S$ ' denote non-significant paths. Where applicable, $\beta 1$ is the estimate value for participants who are not involved in politics, whereas, $\beta 2$ represents coefficients for politically involved respondents.

\section{DISCUSSION}

The aim of the current study is to assess political advertising effectiveness in a wartime context. Our investigation took place in Syria during the 2016 parliamentary elections amidst a longstanding civil war that has cost hundreds of thousands of lives and has displaced half of the 22 million citizens of Syria (CNN, 2017). We conducted an empirical investigation to validate in a wartime context and test a structural path model linking wartime perceptions to voters' behavioural responses via beliefs and attitudes regarding political advertising. Further, we assessed our model invariance regarding voters' level of political involvement. Our study attempts to understand political marketing in the Arab world, and the first research of its kind to investigate wartime perception as a predictor of political advertising effectiveness (which represented by beliefs and attitudes toward advertising) in Syria.

Our results on testing the validity of the belief structure regarding political advertising in Syria show some variance from the one proposed by Jin et al, (2009). Specifically, Jin et al, (2009) elicited a 5-factor set of beliefs about political advertising in the USA. Our confirmatory factor analysis suggests that beliefs held by voters fall within four categories regarding political advertising in Syria namely, information, sarcasm, veracity, and cynicism.

We find that voters' beliefs and attitudes regarding political advertising are negative. Firstly, political advertising is perceived as an unreliable source of information about the candidates. For example, our participants disagree about political advertising as good source of information about candidates' personalities (82\%), and public service record $(77 \%)$, and the policies they support 
$(81 \%)$. Second, our sample respondents feel sarcastic about political advertising. The vast majority of our respondents (72\%) agree on idea that watching political advertisements makes them want to laugh as disparaging remarks. This sense of humour stems from a lack of trust in the government's election promises. Third, veracity levels score low on voters' perceptions of political advertising. Eighty-six per cent of our sample believes that political advertising is dishonest and convoluted. Fourth, Syrian voters feel deeply cynical about political advertising. With the majority of our sample disagreeing with the ability of political advertising to get the public more interested in politics (65\%), increase voter's registration (64\%) and turnout rate (69\%), Syrian voters take a rather view of political advertising. Finally, voters' overall attitude toward political advertising is unfavorable in general, as the majority of our sample dislike political advertising (49\%) and see it as worthless communication $(70 \%)$. It appears then that the conduct of elections in quasidictatorial government regimes conveys a certain degree of legitimacy to the outside world. (Blaydes, 2008).

Whilst or results provide few surprises, since elections tend to reinforce rather than undermine authoritarian regimes, the effect of these elections on consumer affairs is a little less understood. One argument for the relevance of elections conducted by quasi-dictatorships related to the acquisition and distribution of resources. The distribution of such resources to the voting public often becomes the basis of election promises. A Middle Eastern example of such behaviour is provided by Albrecht and Schlumberger (2004) who argue that governments in the Middle East have been subsidising basic foodstuff and consumer goods as election promises since the 1970s. Within a specific Egyptian context, the nation's army employees and their families are provided with ready access to consumer goods and housing that is not easily accessible to other consumers (Blaydes, 2008).

The path model in our study was tested using a structural equation modelling approach. Our findings show that wartime perceptions lead to more unfavourable attitude toward political advertising through increasing the levels of sarcasm especially for voters who are less involved in politics. Further, veracity decreases unfavourable tendencies toward political advertising for less political involved voters, while cynicism exerts negative influence over attitude for those highly involved in politics. Unlike findings in previous research, information is unrelated to attitude. Our path analysis results show attitude toward political advertising as a key precursor of our tested behavioural responses. In summary, a voter's positive attitude toward political advertising will increase chances of watching political advertising, as well as being more willing to vote. The positive influence of attitude on intent to vote can be either direct or indirect, that is, by having a candidate to support which boosts the probability of turnout. These results concur with the observation that the majority of our respondents avoid watching political advertising (62\%), do not have a candidate to support (76\%), and are unwilling to vote $(69 \%)$.

\section{Research Limitations, Practical Implications and Suggestions for Future Research}

We ran our investigation in a country being a political dictatorship during civil war. Thus, the generalisability of our findings would benefit from further research in contexts depicted as quasidictatorships or democracies at war. Thus, the dictatorial level can be conceptualised as a potential moderating variable for the path model. 
Our research is a scholarly attempt to examine political advertising effectiveness in an extreme context, namely, during wartime. The context of the data collection process imposed many constraints on employing a probability sampling procedure. Therefore, we chose snowball sampling to gather as many responses as possible. Non-probability sampling lowers the external validity and consequently the generalizability of research outcomes. We recommend further investigation to be run with a randomized sampling mode, albeit, many risks could accompany the data collection process in a wartime context.

We used a cross-sectional design with all data, unlike in longitudinal studies, collected at one point of time. Cross-sectional studies do not allow for causation (Langdridge, 2004). In this respect, we suggest future empirical investigations to follow a longitudinal design on extending the validity of our model to establish causality on a rigorous basis. Nonetheless, findings generated from a crosssectional study can still be regarded as interpretable and valid as long as they are conducted on a strong theoretical basis (Tharenou et al., 2007). We argue that cross-sectional design is highly recommended for data collection within extreme contexts (e.g., armed conflict zones).

We built our instrument mainly on the work of Jin et al, (2009) Those measures were developed in a western nation with relatively more stable political environment where the communications are fair and open. Thus, even positive ads could be vised as cynical if people did not believe in the system. For example, talking about expanding political freedoms in the Arab world, sixty-seven percent of Arab youth believe that Arab leaders should do more to improve freedom and human rights (Burson-Marsteller (ASDA'A), n.d.). Therefore, eliciting a new structure of beliefs about political advertising within a wartime context or dictatorships using Churchill's (1979) model of developing and validating multi-dimensional scales can improve the external validity of our model in future research. Further, we advise that future research should also follow Churchill's paradigm in constructing a multi-dimensional wartime perception scale that captures views of war for people experiencing and living with it. Finally, our study could have benefited from integrating a supplementary design like content analysis. Thus, such procedure is highly recommended for future research on the advertising that was actually done, which would then allow for a better understanding of what respondents were assessing. Future research could also examine the possible effects of ethnicity and religion in advertising effectiveness during wartime. Such examinations may reveal different ethnic or religious based motives for determining the believability of political advertising campaigns.

\section{REFERENCES}

Albrecht, H., \& Schlumberger, O. (2004). "Waiting for Godot": Regime change without democratization in the Middle East. International Political Science Review, 25(4), 371-392.

Anderson, N. (1981). Foundations of Information Integration Theory. San Diego: Academic Press.

Blaydes, L. (2008, April). Authoritarian elections and elite management: Theory and evidence from Egypt. In Princeton University Conference on Dictatorships.

Brader, T. (2005). Striking a responsive chord: How political ads motivate and persuade voters by appealing to emotions. American Journal of Political Science, 49(2), 388-405.

Bromley, S. (1994). Rethinking Middle East Politics. Austin, TX: University of Texas Press. 
Burson-Marsteller (ASDA'A). (n.d.). Percent of Arab youth that believe Arab leaders should do more to improve freedom and human rights as of 2016. In Statista - The Statistics Portal. Retrieved May 9, 2018, from https://t.co/R9rx5zF5dx

Byrne, B. (2010). Structural Equation Modeling with AMOS: Basic Concepts, Applications, and Programming. New York: Routledge, Taylor \& Francis Group, LLC.

Churchill, G. (1979). A Paradigm for Developing Better Measures of Marketing Constructs. Journal of Marketing Research, 16(1), 64-73.

CNN. (2017). Retrieved August 20, 2017, from https://t.co/Vtk9c1eHRj

Eagly, A. H., \& Chaiken, S. (1998). Attitude Structure and Function. Boston: McGraw-Hill.

Gamson, W. (1992). Talking Politics. Cambridge: Cambridge University Press.

Gleason, M. (1996, April 29). Manning attacks political ads: Fear of government intervention resurrects O'Toole's long crusade. Retrieved June 4, 2017, from Advertising Age: https://t.co/RUKfuAQaer

Global Peace Index. (2018). Retrieved May 23, 2019, from Vision of Humanity: https://t.co/oIW87P0IeC

Goodarzi, J. M. (2009). Syria and Iran: diplomatic alliance and power politics in the Middle East. London: IB Tauris Academic Studies.

Horst, J. (2016). The psychology research companion: From student project to working life. New York: Routledge.

Iyengar, S., \& Prior, M. (2002). Giving advertising a bad name? The effect of political ads on commercial advertising. In B. Norrander, \& C. Wilcox (Eds.), Understanding public (pp. 4360). Washington, DC: CQ Press.

Jin, H., An, S., \& Simon, T. (2009). Beliefs of and attitudes toward political advertising: An exploratory investigation. Psychology \& Marketing, 26(6), 551-568.

Johnston, R., Hagen, M. G., \& Jamieson, K. H. (2004). The 2000 presidential election and thefoundations of party politics. Cambridge: Cambridge University Press.

Kaid, L. L. (2004). Political Advertising. In L. Kaid (Ed.), Handbook of Political Communication Research (pp. 155-202). Beverly Hills, CA: Sage.

Kaid, L. L., \& Holtz-Bacha, C. (1995). Political advertising across cultures. In L. Kaid, \& C. HoltzBacha (Eds.), Political advertising in western democracies: Parties \& candidates on television. Thousand Oaks, California: Sage Publications.

Langdridge, D. (2004). Introduction to research methods and data analysis in psychology. Essex: Pearson Education Limited.

Mahmoud, A. B. (2013). Syrian consumers: Beliefs, attitudes, and behavioral responses to internet advertising. Business: Theory and Practice, 14(4), 297-307.

Mahmoud, A. B. (2015). E-mail advertising in Syria: Assessing beliefs, attitudes, and behaviors. Journal of Promotion Management, 21(6), 649-665. 
Mahmoud, A. B., Grigoriou, N., Fuxman, L., Hack-Polay, D., Mahmoud, F. B., Yafi, E., \& Tehseen, S. (2019). Email is evil! Behavioural responses towards permission-based direct email marketing and gender differences. Journal of Research in Interactive Marketing. Advance online publication.

Mahmoud, A. B., \& Reisel, W. D. (2015). Exploring personal experience of wartime crisis effects on job insecurity in Syria. Psychology of Human Resource Journal, 13(2), 245-256.

Nunnally, J. C., \& Bernstein, I. H. (1994). Psychometric Theory. New York: McGraw-Hill.

Nye, J. S., Zelikow, P., \& King, D. C. (Eds.). (1997). Why People Don't Trust Government. Boston. Harvard University Press.

Parker, G. (2016, July 6). The ASA can't regulate political advertisements. Here's why. Retrieved June 4, 2017, from The Guardian: https://t.co/uZTkzLpa66

Peterson, R. A. (1994). A meta-analysis of Cronbach's coefficient alpha. Journal of Consumer Research, 21, 381-391.

Public Election Law. (2016, Feb 25). Retrieved Jan 7, 2017, from Syrian Arab News Agency: http://sana.sy/?p=342119

Rawwas, M. Y., Patzer, G. L., \& Vitell, S. J. (1998). A cross-cultural investigation of the ethical values of consumers: The potential effect of war and civil disruption. Journal of Business Ethics, 17(4), 435-448.

Stroud, N. J. (2008). Media use and political predispositions: Revisiting the concept of selective exposure. Political Behavior, 30(3), 341-366.

Taber, C., \& Lodge, M. (2006). Motivated skepticism in the evaluation of political beliefs. American Journal of Political Science, 50(3), 755-769.

Tessler, M. (2002). Islam and democracy in the Middle East: The impact of religious orientations on attitudes toward democracy in four Arab countries. Comparative Politics, 34(3), 337-354.

Tharenou, P., Donohue, R., \& Cooper, B. (2007). Management Research Methods (1st ed.). Cambridge: Cambridge University Press.

United Nations. (2016). Report of the Special Rapporteur on the human rights of internally displaced persons on his mission to the Syrian Arab Republic. Retrieved August 4, 2017, from https://t.co/Y9rHATjQcD

Vavreck, L. (2007). The exaggerated effects of advertising on turnout: the dangers of self-reports. Quarterly Journal of Political Science, 2(4), 325-343.

Waller, D. S., \& Polonsky, M. J. (1999). Student attitudes towards political advertising and issues: A cross-cultural study. Journal of International Consumer Marketing, 11(2), 79-98.

Waters, J. (2015). Snowball sampling: a cautionary tale involving a study of older drug users. International Journal of Social Research Methodology, 18(4), 367-380.

Westen, D. (2012, February 19). Why attack ads? Because they work. Retrieved June 4, 2017, from Los Angeles Times: https://t.co/sXWXfgJ4Wq 